\title{
A Versatile Star PEG Grafting Method for the Generation of Nonfouling and Nonthrombogenic Surfaces
}

\author{
Pradeep Kumar Thalla, ${ }^{1,2}$ Angel Contreras-García, ${ }^{3}$ Hicham Fadlallah, ${ }^{1,4}$ \\ Jérémie Barrette, ${ }^{1,2}$ Gregory De Crescenzo, ${ }^{5}$ Yahye Merhi, ${ }^{4}$ and Sophie Lerouge ${ }^{1,2}$ \\ ${ }^{1}$ Laboratory of Endovascular Biomaterials (LBeV), Research Centre, Centre Hospitalier de l'Université de Montreal (CRCHUM), \\ 2099 Alexandre de Sève, Montreal, QC, Canada H2L 2W5 \\ ${ }^{2}$ Department of Mechanical Engineering, École de Technologie Supérieure (ÉTS), 1100 Boulevard Notre-Dame Ouest, \\ Montreal, QC, Canada H3C 1 K3 \\ ${ }^{3}$ Department of Engineering Physics, École Polytechnique de Montreal, P.O. Box 6079, Succ. Centre-Ville, \\ Montreal, QC, Canada H3C 3 A7 \\ ${ }^{4}$ Laboratory of Thrombosis and Haemostasis Research Centre, Montreal Heart Institute, 5000 Belanger Street, \\ Montreal, QC, Canada H1T 1C8 \\ ${ }^{5}$ Department of Chemical Engineering, École Polytechnique de Montreal, P.O. Box 6079, Succ. Centre-Ville, Montreal, \\ QC, Canada H3C $3 A 7$
}

Correspondence should be addressed to Sophie Lerouge; sophie.lerouge@etsmtl.ca

Received 25 August 2012; Accepted 16 November 2012

Academic Editor: Fabienne Poncin-Epaillard

Copyright (C) 2013 Pradeep Kumar Thalla et al. This is an open access article distributed under the Creative Commons Attribution License, which permits unrestricted use, distribution, and reproduction in any medium, provided the original work is properly cited.

Polyethylene glycol (PEG) grafting has a great potential to create nonfouling and nonthrombogenic surfaces, but present techniques lack versatility and stability. The present work aimed to develop a versatile PEG grafting method applicable to most biomaterial surfaces, by taking advantage of novel primary amine-rich plasma-polymerized coatings. Star-shaped PEG covalent binding was studied using static contact angle, X-ray photoelectron spectroscopy (XPS), and quartz crystal microbalance with dissipation monitoring (QCM-D). Fluorescence and QCM-D both confirmed strong reduction of protein adsorption when compared to plasma-polymerized coatings and pristine poly(ethyleneterephthalate) (PET). Moreover, almost no platelet adhesion was observed after $15 \mathrm{~min}$ perfusion in whole blood. Altogether, our results suggest that primary amine-rich plasma-polymerized coatings offer a promising stable and versatile method for PEG grafting in order to create nonfouling and nonthrombogenic surfaces and micropatterns.

\section{Introduction}

Minimizing nonspecific interactions occurring between surfaces and biological species (e.g., proteins and cells) is of paramount importance in many devices including microfluidic, diagnostic, and implantable vascular devices. Indeed, the performance of small-diameter vascular grafts $(<6 \mathrm{~mm})$ made of poly(ethyleneterephthalate) (PET) or poly(tetrafluoroethylene) (PTFE) has been demonstrated to be drastically restricted by thrombotic occlusion, which is initiated by protein and platelet interactions with the graft surface [1]. Surface modification, by incorporation of hydrophilic polymers such as polyethylene glycol (PEG), has been shown to reduce nonspecific protein adsorption $[1,2]$. PEG presents several advantages since it is a water soluble, synthetic, nonimmunogenic [3], and nontoxic [4] polymer approved by the FDA for internal consumption [5]. Furthermore, PEG coatings have been reported to exhibit low degree of protein adsorption [2] and platelet or cell adhesion [6]. Finally, PEG end-groups can also be used to graft biomolecules harboring desirable activities [7].

Several strategies have been proposed for PEG immobilization on biomaterial surfaces, including simple direct adsorption [8], radiation and chemical cross-linking 
approaches [9], and self-assembled monolayers [10]. In most cases, these approaches were shown to improve repellence of proteins and platelets in vitro, but results were variable and PEG coating sometimes failed to perform equally well in vivo [11], most likely due to insufficient stability of the PEG coating [12]. These results strongly suggest that the grafting method is an important design criterion in order to achieve both coating stability and performance. While simple adsorption is flexible and convenient, its efficacy is limited by the tendency of PEG to elute off the surface [13]. Stable PEG coatings generated by direct covalent chemical coupling to substrates have already been reported [14]. However, this approach is far from being versatile since it relies on the availability of compatible functional groups on both PEG and the host surface as well as on their respective surface densities.

In addition to the grafting method, the type of PEG molecule and its density after grafting play key roles in the prevention of protein adsorption: resistance to protein adsorption mainly depends on PEG chain length, grafting density, hydration, surface charge and conformation [15]. In this regard, star-shaped or multiarm PEGs are advantageous because of their molecular architecture and long chain length, which enable higher grafting density than with linear PEG $[7,16,17]$. Additionally, star PEG offers high density of functional groups that allow subsequent grafting of selected biomolecules designed to further tailor surface properties [7, 17]. Here, we present a novel method for grafting stable star PEG, which can be applied to a large variety of biomaterials (polymers, ceramics, metals and semiconductors used in biomedical applications); it also enables one to create various deposit geometries such as micro-patterns. To achieve this goal, we took advantage of stable primary amine-rich plasmapolymerized thin film coatings, developed and characterized previously in our laboratories as reported in [18-20]. More specifically, a low-pressure plasma-polymerized coating prepared from a mixture of ethylene and ammonia (hereafter "LP"), with high concentrations of nitrogen $([\mathrm{N}]=16 \%)$ and primary amines $\left(\left[\mathrm{NH}_{2}\right]=7.5\right)[18,20]$, has been used. In the present work, the ability of this coating, combined with star PEG to create protein and platelet-repellent surfaces, has been studied. Covalent coupling of star PEG was first investigated on amino-coated glass substrates to optimize the method, as assessed by static contact angle and XPS analysis. Next, PEG coatings were created on LP-coated quartz crystals for protein adsorption studies by quartz crystal microbalance with dissipation monitoring (QCM-D). Finally, the ability of PEG coatings to decrease protein adsorption and platelet adhesion on PET films was confirmed by fluorescence microscopy and an in vitro perfusion platelet adhesion assays, respectively.

\section{Materials and Methods}

2.1. Chemicals and Reagents. Amino-coated glass slides $\left(10 \times 10 \mathrm{~mm}^{2}\right)$ were purchased from Erie Scientific Co. (Portsmouth, NH, USA), and $50 \mu \mathrm{m}$-thick poly (ethyleneterephthalate) (PET) film was purchased from
Goodfellow (Huntingdon, England). Albumin Texas Red conjugate, Fibrinogen, PBS ( $\mathrm{pH} 7.4)$, prostacyclin $\left(\mathrm{PGI}_{1}\right)$, and Hanks' Balanced Salt Solution (HBSS) were obtained from Sigma Aldrich Canada Ltd. (Oakville, ON, Canada). A 4-arm PEG with N-hydroxy succinimide (NHS) terminal functional groups (PEG-NHS; $\mathrm{MW}=10 \mathrm{kDa}$ ) was purchased from Creative PEG Works Inc. (Winston Salem, NC, USA). Parallel bar grids $3.05 \mathrm{~mm}$ in diameter were purchased from Electron Microscopy Sciences (Hatfield, PA, USA).

\subsection{Coating Preparation}

2.2.1. Plasma Polymerization. Plasma-polymerized ethylene coatings containing bonded nitrogen (LP) were deposited on PET and on gold-plated QCM-D crystal surfaces using a lowpressure radio-frequency (R.F.) glow-discharge plasma reactor, as extensively described elsewhere [18]. Briefly, a mixture of anhydrous ammonia $\left(\mathrm{NH}_{3}\right)$ and ethylene $\left(\mathrm{C}_{2} \mathrm{H}_{4}\right)($ of $99.9 \%$ and $99.5 \%$ purity, resp., Air Liquide Canada Ltd., Montreal, QC) was admitted into a cylindrical aluminum/steel reactor chamber at flow rates of 15 and 20 standard cubic centimeters per minute $(\mathrm{sccm})$, respectively. This gas ratio $(R=0.75)$ was based on a recent study that revealed high concentrations of nitrogen $([\mathrm{N}]=16 \%)$ and primary amines $\left(\left[\mathrm{NH}_{2}\right]=7.5 \%\right)$ a smooth surface, and good stability in air and in aqueous solvents [20] in the resulting coating, along with very low solubility. The low-power $(P=10 \mathrm{~W})$ plasma was created at a pressure of $80 \mathrm{~Pa}$, resulting in a negative dc bias voltage of $-40 \mathrm{~V}$. The duration of deposition, $10 \mathrm{~min}$, led to $80-90 \mathrm{~nm}$ thick LP coatings.

2.2.2. Grafting of Star PEG. The PEG grafting procedure was performed on both amino-coated glass slides and on LPcoated surfaces. Of course, both contained primary amines with which the N-hydroxy succinimide (NHS) terminal groups on PEG readily react under slightly basic conditions $(\mathrm{pH}=8.5)$ to form stable amide bonds [21], as shown in Figure 1. Prior to PEG grafting, the aminated glass slides were cleaned, in order to remove organic contaminants, using chloroform (99\% purity, Fisher Scientific) for 2 min, followed by rinsing twice with Milli-Q water in an ultrasonic bath and drying with a flow of compressed nitrogen. PEGNHS solutions at different concentrations $(0.55,1.66,5$, and $15 \% \mathrm{w} / \mathrm{v})$ were prepared by dissolving in $0.025 \mathrm{M}$ phosphate buffer $\left(0.025 \mathrm{M} \mathrm{NaH}_{2} \mathrm{PO}_{4}+0.025 \mathrm{M} \mathrm{Na}_{2} \mathrm{HPO}_{4}\right.$, with drops of $0.01 \mathrm{M} \mathrm{NaOH}$ to adjust to $\mathrm{pH} 8.5$ ). In order to prevent hydrolysis of NHS terminal groups, the PEG solution was immediately deposited on aminated surfaces for $2 \mathrm{~h}$ at room temperature. The PEG solution was then removed, and the slides were rinsed for 2 min with PBS, followed by Milli-Q water (2 times) in an ultrasonic bath. Finally, the slides were dried with nitrogen gas stream.

\subsection{Surface Characterization}

2.3.1. X-Ray Photoelectron Spectroscopy (XPS). The chemical composition of PEG-modified surfaces was characterized by XPS using a VG ESCALAB 3 MkII instrument with 


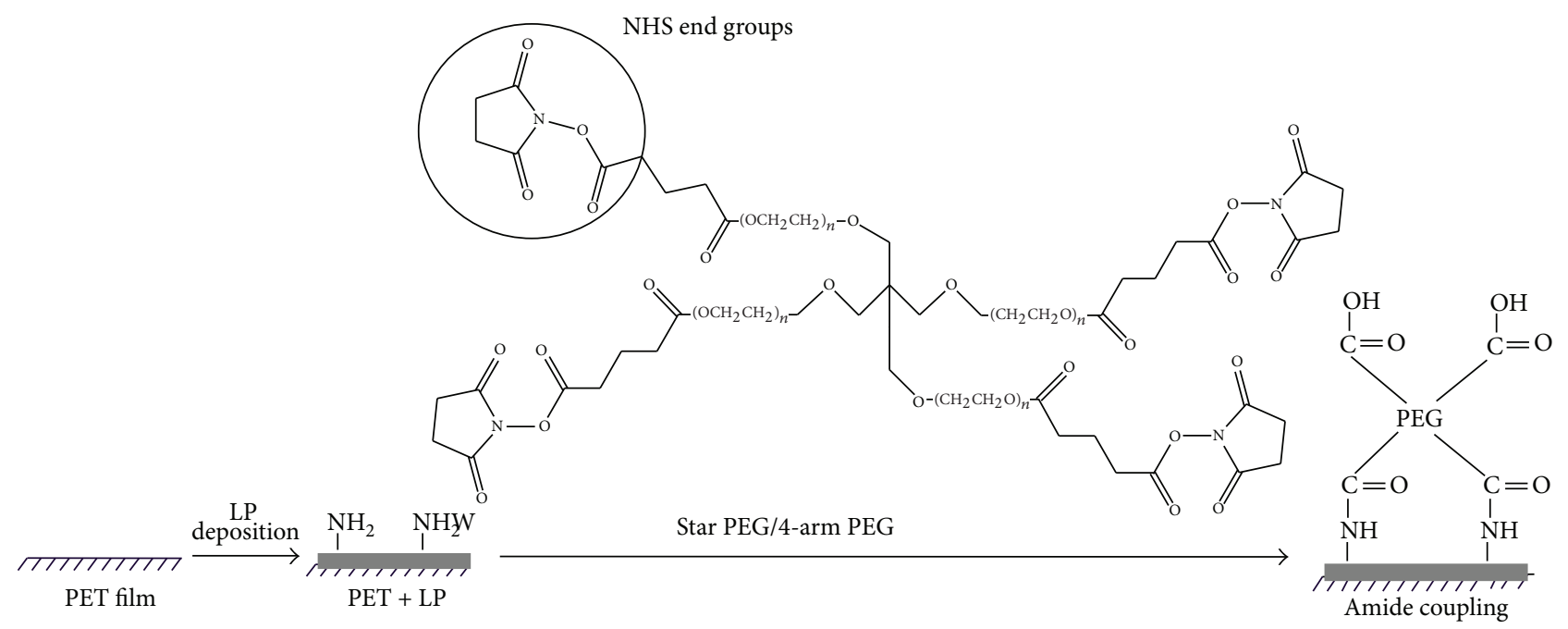

FIGURE 1: Schematic diagram of star PEG covalent binding reaction. Either one or two N-hydroxyl succinamide (NHS) terminal groups of star PEG react directly with primary amines through ester-amine reactions to form stable amide bonds; the remaining terminal groups do not participate in coupling, due to steric constraints [22] and hydrolyze to carboxylic acid groups during the reaction.

nonmonochromatic $\mathrm{Mg} \mathrm{K} \alpha$ radiation. To minimize the effect of the substrate, spectra were acquired at a $70^{\circ}$ take-off angle. For each sample, survey $(0-1200 \mathrm{eV})$ and high-resolution spectra for $\mathrm{C} 1 \mathrm{~s}$ and $\mathrm{O} 1 \mathrm{~s}$ were recorded at pass energy of $100 \mathrm{eV}$ and $20 \mathrm{eV}$, respectively. Charging was corrected by referencing all peaks with respect to the carbon $(\mathrm{C} 1 \mathrm{~s}) \mathrm{C}-\mathrm{C}$, $\mathrm{C}-\mathrm{H}$ peak at $285.0 \mathrm{eV}$. Advantage v4.12 software (Thermo Electron Corporation, Waltham) was used to quantify the constituent elements after Shirley-type background subtraction, by integrating the areas under relevant peaks.

2.3.2. Static Water Contact Angle. The wettability of the aminated glass and LP-deposited surfaces before and after PEG grafting was assessed by static water contact angle measurements, using a Ramé-Hart Inc., Model 100-00 115 goniometer. Three measurements were taken on each surface using Milli-Q water as probe liquid ( $2 \mu \mathrm{L}$ drop size), and the experiments were repeated on three independent samples.

\subsection{Protein Adsorption Studies}

2.4.1. QCM-D. QCM-D (Model Q-sense E4, Q-Sense AB, Sweden) was used to monitor fibrinogen adsorption on LP and star PEG-grafted surfaces. This technique has been recognized as a sensitive tool to investigate protein adsorption since it allows real-time followup of mass and viscoelastic properties of the adsorbed layer by measuring the changes in frequency and energy dissipation of an oscillating quartz crystal [23]. Gold-quartz crystals (5 MHz, Q-sense AB, Sweden) were coated with LP followed or not by star PEG grafting using PEG solutions of various concentrations ( 0.55 , $1.66,5$, and $15 \% \mathrm{w} / \mathrm{v}$ ) as described above. QCM-D assay was performed at $37^{\circ} \mathrm{C}$ using human fibrinogen $(340 \mathrm{kDa})$ solution $(0.5 \mathrm{mg} / \mathrm{mL}$ in PBS). Crystals were first exposed to PBS with a flow rate of $50 \mu \mathrm{L} / \mathrm{min}$ until a stable baseline was reached for frequency and dissipation; a fibrinogen solution was then flowed for $2 \mathrm{~h}$ followed by rinsing with PBS for $30 \mathrm{~min}$. Protein adsorption on 4 different surfaces was compared each time by following changes in frequency $(\Delta f)$ and dissipation $(\Delta D)$, and each surface was tested at least three times.

Since adsorbed protein forms a viscoelastic film, the Sauerbrey relation overestimates the real mass of adsorbed proteins onto the surface [24]. The Voigt viscoelastic modeling in QTools (Q tools, Q-sense AB, Sweden) was thus applied to estimate the adsorbed mass per surface unit by considering both frequency $(\Delta f)$ and dissipation $(\Delta D)$ shifts [24]. All the overtones were used except the first one to normalize the data and to estimate the adsorbed mass of protein. It is important to note that the estimated mass included protein molecules in addition to water trapped in the layer. The following parameters were used for modeling the data as described by Weber et al. [25]. The layer density was fixed at $1200 \mathrm{~kg} / \mathrm{m}^{3}$. Parameters fitted were (i) layer viscosity between 0.001 and $0.01 \mathrm{~kg} / \mathrm{ms}$ and (ii) layer thickness between $10^{-10}$ and $10^{-7} \mathrm{~m}$.

The stability of the coating was assessed by incubating 5\% PEG-grafted crystals in $\mathrm{PBS}\left(37^{\circ} \mathrm{C}, \mathrm{pH} 7.4,5 \% \mathrm{CO}_{2}\right)$ up to 4 weeks. Samples were then rinsed with Milli-Q water and dried with nitrogen gas. QCM-D assay was performed as described previously to compare fibrinogen adsorption on LP $(n=1)$ with that on 5\% PEG was immersed for 1 day $(n=1)$, or for 4 weeks in PBS $(n=2)$. The experiment was performed in triplicate. Between each experiment, gold crystals were extensively cleaned to remove LP and PEG for subsequent experiment. Crystals were cleaned by incubating them for $15 \mathrm{~min}$ in a solution containing Milli-Q water, ammonia, and hydrogen peroxide (ratio of $5: 1: 1,75^{\circ} \mathrm{C}$ ), followed by extensive rinsing with Milli- $\mathrm{Q}$ water. Then they were dried with $\mathrm{N}_{2}$ gas stream and exposed to UV and ozone for $10 \mathrm{~min}$ in a UV/ozone ProCleaner (Bioforce 
Nanosciences, Inc. Model ProCleaner 110), as reported in [26].

2.4.2. Fluorescence Measurements. To confirm these results on more realistic surfaces and, simultaneously, confirm the non-fouling properties with a smaller protein size, albumin $(66 \mathrm{kDa})$ adsorption on bare PET, LP- and LP-PEG-coated PET was studied using fluorescence microscopy. The samples were immersed into a solution of Albumin Texas Red conjugate $(0.2 \mathrm{mg} / \mathrm{mL}$ in $\mathrm{PBS})$ for $2 \mathrm{~h}$ at room temperature (surfaces being protected from light exposure). Surfaces were then washed thoroughly with PBS to remove unbound protein, dried with a stream of nitrogen and examined under a fluorescence microscope (Nikon Eclipse E600 mounted with a Photometrics CoolSnap HQ2 CCD camera) at 10x magnification. Fluorescence intensity (fluorescence excitation and emission of 596 and $615 \mathrm{~nm}$, resp.), which directly correlated with the amount of albumin adsorbed on the surface [27], was measured using the NIS-Elements AR (version 3.0) Nikon software, and the background was subtracted for each sample. Intensity for fluorescence measurements is given as counts per second (cps).

2.4.3. Micro Patterning. The ability to generate nonfouling microscale patterns on PET substrate was investigated using LP deposition. Micro-patterns were generated by placing electron microscopy grids (consisting of $184 \mu \mathrm{m}$ wide parallel bars separated by $92 \mu \mathrm{m}$ ) over PET substrates before LP deposition. Then, PEG grafting was performed by covalent binding, and unbound PEG was removed by rinsing with PBS in an ultrasonic bath as explained above. Samples were then immersed in Albumin Texas Red conjugate $(0.2 \mathrm{mg} / \mathrm{mL}$ in PBS $)$ for $2 \mathrm{~h}$ at room temperature, and surfaces were washed thoroughly with PBS to remove unbound protein. Finally, substrates were examined by fluorescence microscopy.

\subsection{Platelet Adhesion}

2.5.1. Platelet Isolation and Labeling. Platelet adhesion on control and modified surfaces was evaluated by perfusion tests using radiolabeled platelet in fresh human blood. This part of the study has been approved by the human ethical committee of the Montreal Heart Institute. All subjects gave informed consent and were free from drugs interfering with platelet function for at least 2 weeks before blood sampling. Platelet isolation and labeling as well as the perfusion experiments were conducted as described previously [28]. A $60 \mathrm{~mL}$ sample of venous blood from each subject was anticoagulated with $6 \mathrm{~mL}$ of D-PhenylalanylL-prolyl-L-arginine chloromethyl ketone (PPACK) in saline (50 nM final concentration, Calbiochem, QC, Canada), and a $30 \mathrm{~mL}$ with anticoagulant citrate dextrose (ACD, Baxter, Mississauga, Canada). The ACD blood was used to isolate and radiolabel platelets. Briefly, platelet-rich plasma (PRP) was isolated by centrifugation for $15 \mathrm{~min}$ at $1800 \mathrm{rpm}$. PRP was then centrifuged for $10 \mathrm{~min}$ at $2200 \mathrm{rpm}$ to separate platelets from platelet-poor plasma (PPP). The pellet of platelets was suspended with Hanks' Balanced Salt Solution (HBSS) containing $0.5 \mu \mathrm{g} / \mu \mathrm{L}$ of prostaglandin E1 $\left(\mathrm{PGE}_{1}\right)$ and centrifuged for $10 \mathrm{~min}$ at $2200 \mathrm{rpm}$. The platelet pellet was resuspended with $2 \mathrm{~mL}$ of HBSS containing $\mathrm{PGE}_{1}$ and incubated with $250 \mu \mathrm{Ci}$ of Indium ${ }^{111}$ Oxine (GE Healthcare Canada Inc., Burlington, Ontario) for $15 \mathrm{~min}$ at room temperature, followed by centrifugation for $8 \mathrm{~min}$ at $2100 \mathrm{rpm}$. The supernatant was removed and the radiolabeled platelet pellet resuspended in $10 \mathrm{~mL}$ of PPP and finally mixed with the $60 \mathrm{~mL}$ of the PPACK blood. Platelet count of each sample was measured using Coulter Act Diff cell counter (Beckman Coulter, Canada). For reference, $10 \mu \mathrm{L}$ of blood containing labeled platelets was measured using a gamma counter (Minaxi 5000, Packard Instruments).

2.5.2. Platelet Adhesion. Platelet adhesion was conducted using plexiglas perfusion chambers that mimic the tube-like cylindrical shape of blood vessels, as described previously [28, 29]. The samples (bare PET, LP-coated PET, and PEG-coated PET prepared with 5\% w/v PEG were placed in the perfusion chambers containing a window of $2 \mathrm{~mm}$ internal diameter $\times 10 \mathrm{~mm}$ long, permitting direct exposure of the samples to the blood. The connection between the chambers and the peristaltic pump was performed using nontoxic and nonpyrogenic Tygon flexible surgical tubes (Tygon R-100, Fisher Scientific, Canada). A thermostatically controlled water bath was used to maintain the perfusion system at $37^{\circ} \mathrm{C}$. The samples within the perfusion chambers were directly exposed to the blood containing ${ }^{111}$ in labeled platelets for $15 \mathrm{~min}$ at a flow rate of $40 \mathrm{~mL} / \mathrm{min}$ and a shear rate of $853 \mathrm{sec}^{-1}$, followed by rinsing with a buffered formalin solution for fixation. At the end of each experiment, the radioactivity on the exposed surfaces was measured using a gamma counter (Minaxi 5000, Packard Instruments). Platelet adhesion on each test surface was calculated from the known radioactivity of reference and platelet count in the blood in count per minute (cpm), using the following equation:

$$
\text { Platelet adhesion }=\frac{\left({ }^{111} \text { In cpm in exposed segment }\right) \times(\text { No. of platelets } / \mathrm{mL} \text { blood }) /{ }^{111} \mathrm{In} \mathrm{cpm} / \mathrm{mL} \text { blood }}{\text { exposed surface }\left(\mathrm{cm}^{2}\right)} .
$$

The experiment was repeated for each test surface using three different healthy blood donors. Results were also compared to fresh endothelium and injured arterial surfaces.
2.5.3. Scanning Electron Microscopy. After platelet adhesion assay, each surface was observed by scanning electron microscopy (SEM) to assess platelet adhesion and 
morphology. The specimens were dehydrated through a series of graded ethanol solutions $(30 \%, 50 \%, 70 \%, 95 \%$, and $2 \times 100 \% \mathrm{v} / \mathrm{v}$ ) and subjected to $\mathrm{CO}_{2}$ critical point drying (E3000, Polaron, Quorum Technologies). The dried specimens were finally sputter-coated with gold and observed under SEM using a Hitachi S-3600N (Hitachi HighTechnologies, Canada).

2.6. Statistical Analysis. All the results were expressed as mean \pm standard deviation. Statistical analysis was carried out using one-way ANOVA analysis followed by Tukey's post hoc test. Student's $t$-test was used when comparing two groups. $P<0.05$ was considered to be statistically significant.

\section{Results}

3.1. Surface Characterization. In order to evaluate the efficiency of our PEGylation protocol, water contact angles were measured on aminated glass before and after PEG (Figure 2). While aminated glass exhibited a relatively hydrophilic surface $\left(54.9 \pm 1.1^{\circ}\right)$, the contact angle significantly decreased after star PEG grafting as a function of its coupling concentration. As can be seen in Figure 2, no significant difference was observed between 5 and 15\%; very similar results were obtained for PEG grafting on PET films after LP deposition (data not shown). LP coatings, on their own, exhibited a contact angle of about $56.1 \pm 0.6^{\circ}$.

XPS measurements further confirmed star PEG presence after the covalent coupling procedure on aminated glass surfaces. Survey scans were used to study changes in elemental composition of modified and unmodified substrates. Table 1 shows the decrease of silicon (Si) and Nitrogen (N) concentration, in parallel to the increase in carbon (C) on all PEG-modified surfaces, indicating the presence of PEG. These results were further confirmed by highresolution $\mathrm{C} 1 \mathrm{~s}$ and $\mathrm{O} 1 \mathrm{~s}$ scans. As shown in Figure 3(a), four different peaks were identified on the aminated glass control; the main two peaks (binding energies of $285 \mathrm{eV}$ and $284 \mathrm{eV}$ ) corresponded to carbon-carbon (C-C) and carbonsilicon $(\mathrm{C}-\mathrm{Si})$ bonding, respectively. The low-intensity peak around $286.3 \mathrm{eV}$ was attributed to a mixture of $\mathrm{C}-\mathrm{N}$ and $\mathrm{C}-\mathrm{O}$ bonds, for which binding energies are too close to be discriminated. This peak most likely came from the amination process used by the manufacturer, since commercial aminated glass substrates are generally produced by amino silylation using amino propyl triethoxy/methoxy silane. Therefore, it is probable that this peak combine $\mathrm{C}-\mathrm{O}$ (from triethoxy) and $\mathrm{C}-\mathrm{N}$ (from $\mathrm{C}-\mathrm{NH}_{2}$ end groups) groups. The other small intensity peak at higher energy level $(288.4 \mathrm{eV})$ was attributed to the presence of carboxyl groups resulting from surface contamination [16]. Highresolution scans of all-star PEG-grafted surfaces presented a large increase of the peak around $286.5 \mathrm{eV}$, in agreement with the presence of $\mathrm{C}-\mathrm{O}$ bond in PEG. As can be seen in Figures 3(b)-3(e), the relative intensity of this peak increased with star PEG coupling concentration, hence highly suggesting that the density and/or thickness of PEG coating increased

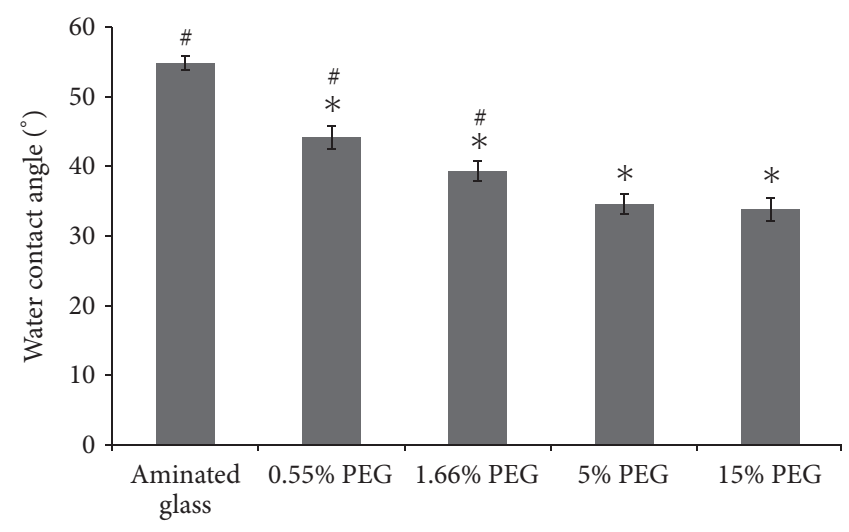

FIGURE 2: Static water contact angles on unmodified aminated glass and after PEG grafting using PEG solution at concentrations of $0.55,1.66,5$, and $15 \% \mathrm{w} / \mathrm{v}$. Results are expressed as mean $\pm \mathrm{SD}$, $n=3$. * Significantly different from aminated glass $(P<0.001)$ \# Significantly different from 5\% PEG $(P<0.001)$.

TABle 1: Surface elemental concentration (in At.\%) of C, O, Si, and $\mathrm{N}$, as determined by XPS on aminated glass and PEG-modified surfaces using various star PEG coupling concentrations.

\begin{tabular}{lcccc}
\hline Surface & $\mathrm{O} \%$ & $\mathrm{C} \%$ & $\mathrm{Si} \%$ & $\mathrm{~N} \%$ \\
\hline Aminated glass & 40.9 & 36.6 & 17.0 & 4.8 \\
0.55\% PEG & 38.3 & 44.5 & 12.7 & 3.7 \\
1.66\% PEG & 37.4 & 46.8 & 11.8 & 3.3 \\
5\% PEG & 36.1 & 50.3 & 10.1 & 3.1 \\
15\% PEG & 37.4 & 48.1 & 11.1 & 2.8 \\
\hline
\end{tabular}

with PEG concentration. XPS analysis was also performed on LP surfaces. However, due to the complexity of LP composition, in particular the presence of $\mathrm{C}-\mathrm{N}$ bond, whose binding energy is close to that of $\mathrm{C}-\mathrm{O}$ groups in $\mathrm{PEG}$ [30], we were unable to conclude about $\mathrm{C}-\mathrm{O}$ increase on these substrates.

3.2. Protein Adsorption Studies. The non-fouling properties of our LP-PEG coatings were first investigated by monitoring fibrinogen adsorption using QCM-D. Figure 4 presents an example of change in resonance frequency $(\Delta f)$ and dissipation $(\Delta D)$ when LP- and PEG- (5\%) coated Quartz crystals were exposed to a solution of fibrinogen $(0.5 \mathrm{mg} / \mathrm{mL})$. On LP surfaces, introduction of the fibrinogen solution led to rapid decrease of the resonance frequency, indicating fibrinogen adsorption, while the related increase in dissipation indicated that the adsorbed protein layer was viscous. A subsequent rinse with $\mathrm{PBS}(\mathrm{pH}$ 7.4) induced only slight changes, indicating that only a small amount of bound fibrinogen was dissociated when rinsing with buffer, and most of the protein was irreversibly adsorbed [23]. $\Delta f$ and $\Delta \mathrm{D}$ were much reduced on PEG-modified surface. Typical mass variation over time with the various $P E G$ concentrations is presented in Figure 5. The reduction in fibrinogen adsorption resulting from the various PEGylation treatments, compared to pristine LP surfaces are summarized in Table 2. Fibrinogen adsorption decreased with rising PEG 


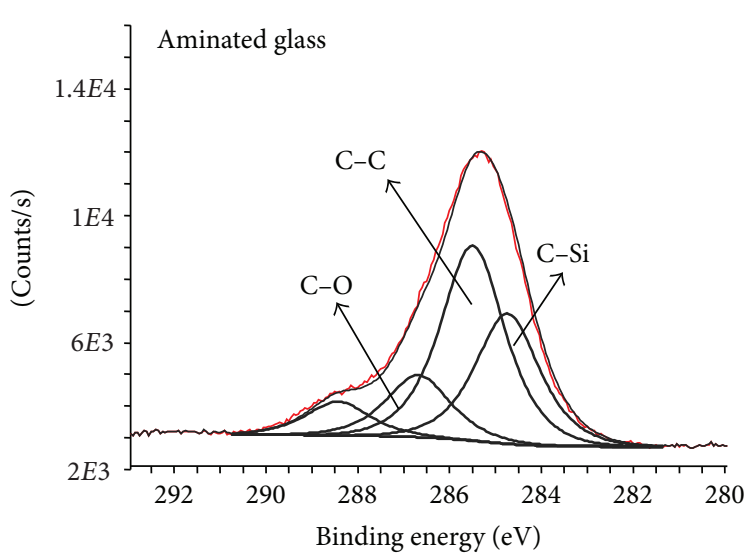

(a)

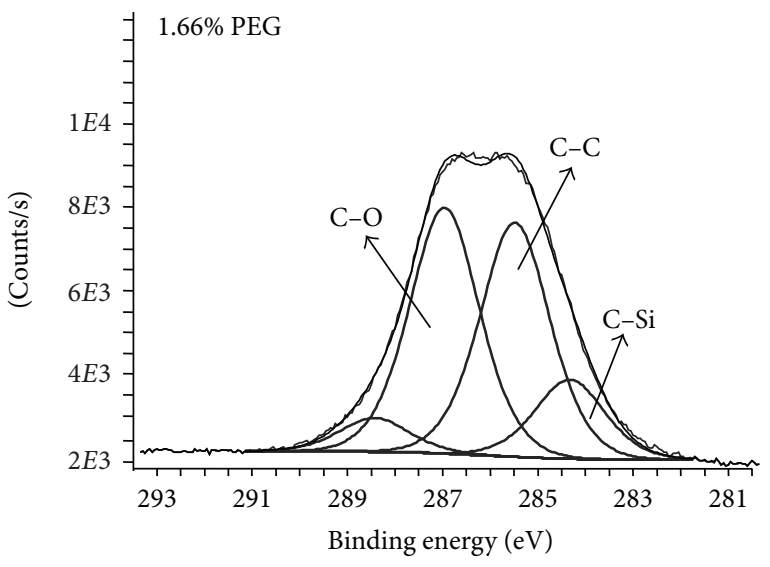

(c)

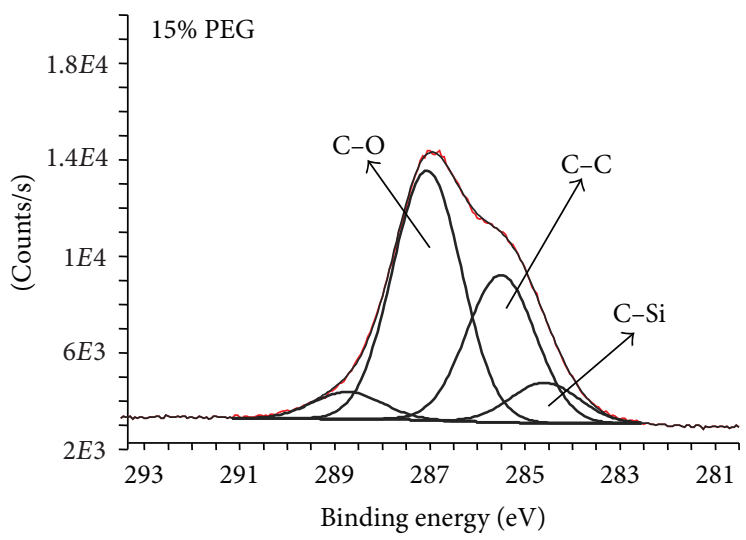

(e)

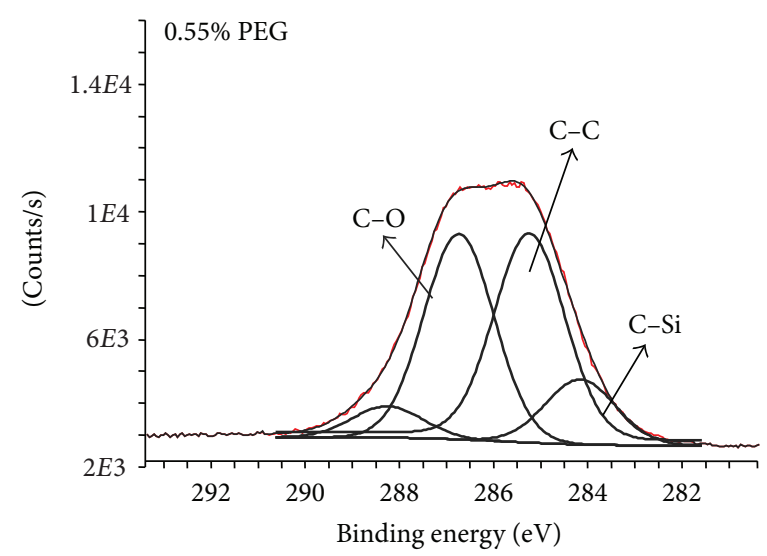

(b)

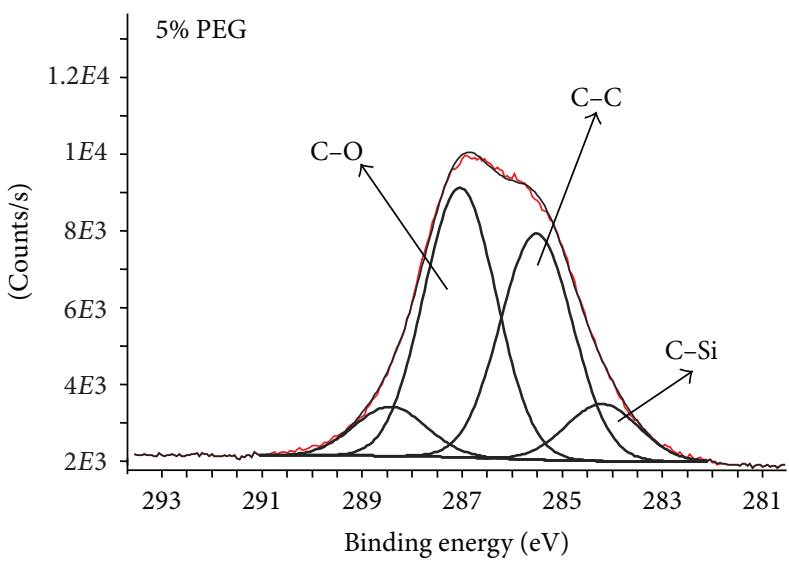

(d)

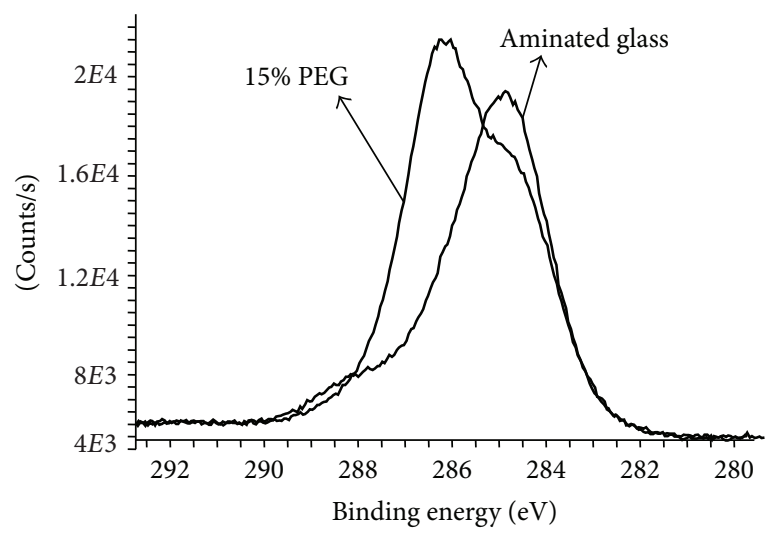

(f)

FIGURE 3: XPS high-resolution C1s scans of aminated glass (a) before and (b-e) after star PEG grafting at various coupling concentrations $(0.55,1.66,5$, and $15 \% \mathrm{w} / \mathrm{v})$. Note that the relative intensity of the C-O peak increased with the PEG coupling concentration; (f) Overlay spectra of $15 \%$ PEG-modified on unmodified aminated surface.

concentration, reaching a maximum reduction of $79 \pm 11 \%$ for 5\% w/v PEG solution. Increasing PEG concentration from $5 \%$ to $15 \%$ did not result in a significant difference in subsequent fibrinogen adsorption $(P=0.78)$. Finally, after 4 weeks of immersion in PBS, 5\% PEG-coated surface still exhibited strong reduction of fibrinogen adsorption $(89 \pm 7 \%)$ compared to LP (Table 2 and Figure 6).
In parallel, Texas Red conjugated albumin $(66 \mathrm{kDa}$, $0.2 \mathrm{mg} / \mathrm{mL}$ ) adsorption in static condition was also investigated using fluorescence microscopy in order to allow comparison with PET surfaces (Figure 7). Since no significant difference had been observed by QCM-D between 5\% and $15 \%$ PEG conditions, only coatings obtained with in-solution concentrations of PEG up to 5\% were compared to LP and 


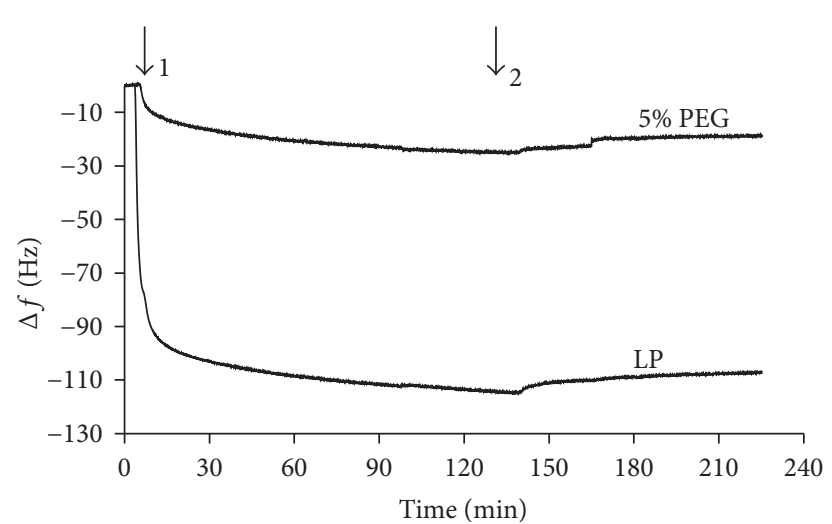

(a)

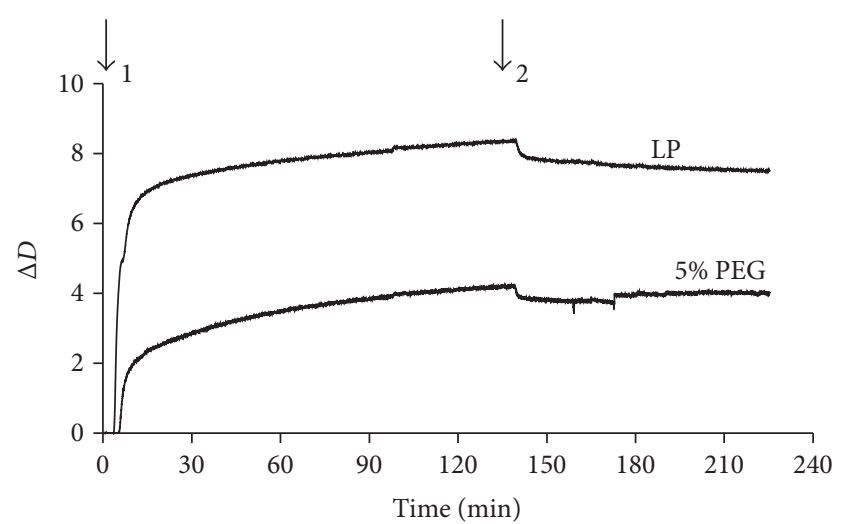

(b)

FIGURE 4: QCM-D real-time change in resonance frequency $(\Delta f)$ and dissipation $(\Delta D)$ related to modified (5\% PEG) and unmodified LP surfaces upon exposure to fibrinogen solution $(0.5 \mathrm{mg} / \mathrm{mL}$; (1)) followed by rinsing with PBS (2).

TABLE 2: Percentage of reduction of fibrinogen $(0.5 \mathrm{mg} / \mathrm{mL})$ adsorption compared to LP surface for different coupling concentrations of star PEG. Results are expressed as mean $\pm \mathrm{SD}, n=4$.

\begin{tabular}{lc}
\hline Surface & $\begin{array}{c}\text { Reduction of fibrinogen adsorption } \\
(\%)\end{array}$ \\
\hline $15 \%$ PEG & $76 \pm 18$ \\
$5 \%$ PEG & $79 \pm 11$ \\
$1.66 \%$ PEG & $64 \pm 11$ \\
$0.5 \%$ PEG & $34^{*}$ \\
\hline $5 \%$ PEG after 4 weeks in PBS & $89 \pm 7 \%$
\end{tabular}

${ }^{*}$ Result expressed as a mean; $n=2$ only.

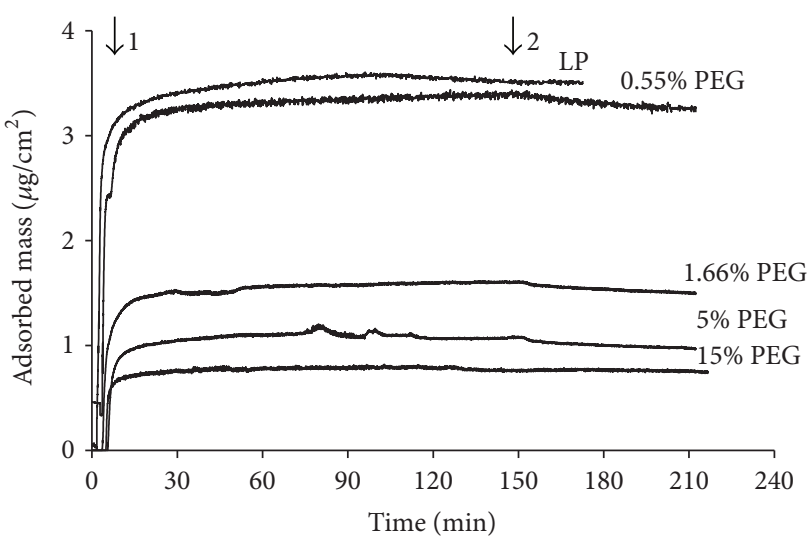

FIGURE 5: Time-resolved effect of various PEG coupling concentrations on fibrinogen $(0.5 \mathrm{mg} / \mathrm{mL})$ adsorption. QCMD data were analyzed according to the Voigt model. Time of fibrinogen injection (1) and rinsing with PBS (2) are indicated.

to bare PET surfaces. While LP coating increased albumin adsorption compared to bare PET films, further PEG grafting strongly decreased protein adsorption. PEG coatings were even effective at low in-solution PEG concentrations, $\mathrm{d}$ and the amount of albumin adsorption decreased as PEG coupling concentrations were increased. Of interest, all

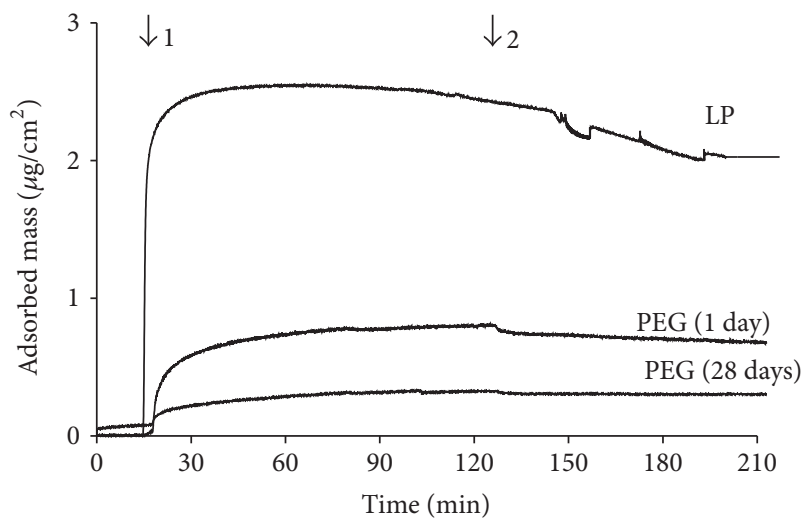

FIGURE 6: Fibrinogen $(0.5 \mathrm{mg} / \mathrm{mL})$ adsorption on LP and on PEGmodified surfaces immersed in PBS over a period of 1 or 28 days. QCMD data were analyzed according to the Voigt model. Time of fibrinogen injection (1) and rinsing with PBS (2) are indicated.

PEG concentrations enabled to decrease albumin adsorption below PET control $(P<0.001)$. On 5\% PEG, fluorescence was decreased by $92 \%$ and $88 \%$ compared to LP and PET, respectively.

Texas Red conjugated albumin was also used to demonstrate the applicability of our LP deposition method to the generation non-fouling micro-patterns (Figure 8). While only slight difference was observed between PET and PET+LP coated regions (Figure 8(a)), subsequent PEG grafting led to non-fouling areas clearly distinct from bare PET regions that manifested strong adsorption (Figure $8(\mathrm{~b})$ ).

3.3. Platelet Adhesion. The levels of platelet adhesion on the various surfaces after 15 minutes exposure to whole blood under perfusion are presented on Figure 9. As expected, LP coating on PET significantly increased platelet adhesion when compared to pristine PET $\left(2060 \times 10^{3}\right.$ versus $244 \times 10^{3}$ platelets $/ \mathrm{cm}^{2}$ ); these levels were, however, much lower than those corresponding to injured arterial tissues 


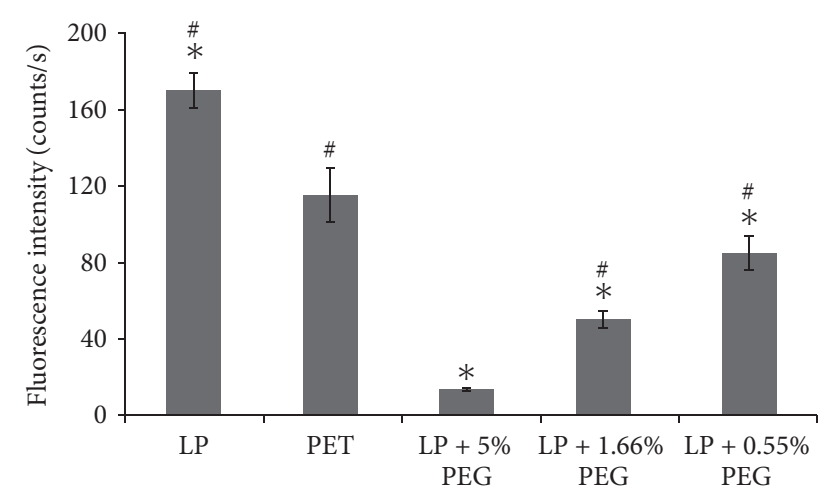

FIgURE 7: Fluorescence detection of adsorbed Texas Red labeled albumin $(0.2 \mathrm{mg} / \mathrm{mL})$ on bare PET, LP alone, and LP-PEG-coated PET. Results are expressed as mean \pm SD $(n=4)$. Background was subtracted from each surface. ${ }^{*}$ Significantly different from PET $(P<0.001)$, "Significantly different from LP+ 5\% PEG $(P<0.001)$.

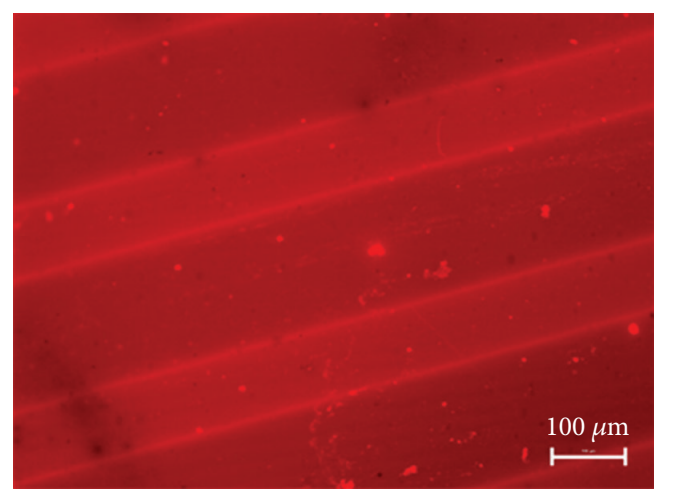

(a)

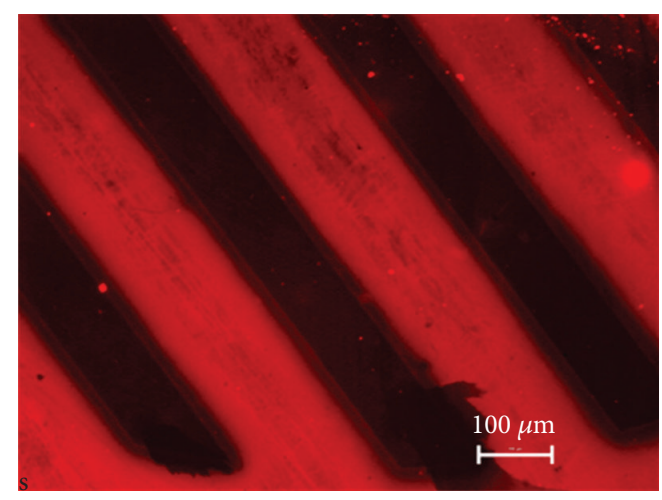

(b)

FIGURE 8: Fluorescence microscopy images of LP micro-patterns on PET surfaces after exposure to albumin Texas Red conjugate. Parallel pattern surface (a) without PEG grafting and (b) modified with PEG.

$\left(15,195 \times 10^{3}\right.$ platelets $\left./ \mathrm{cm}^{2}\right)$. Of interest, PEG grafting $(5 \%$ PEG solution) on LP drastically decreased LP surface thrombogenicity, reaching levels about 10 times lower than those determined for bare PET control surfaces $\left(25 \times 10^{3}\right.$ versus $244 \times 10^{3}$ platelets $\left./ \mathrm{cm}^{2} ; P<0.001\right)$. Direct observation of each individual surface using SEM (Figure 10) confirmed that

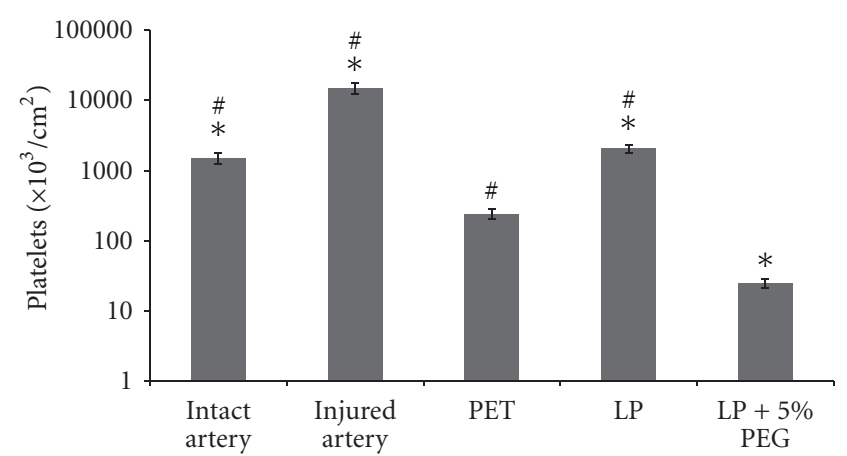

FIGURE 9: Platelet adhesion on an intact artery, injured artery, PET film, LP and 5\%PEG- modified substrates. Results are expressed on a logarithmic scale, as mean \pm SD $(n=4)$. * Significantly different from PET $(P<0.001)$ " Significantly different from LP + 5\% PEG $(P<0.001)$.

platelet adhesion was almost abolished on PEG surfaces, since no platelets were observed on these surfaces. In contrast, relatively high level of platelet adhesion was noticed after LP treatment and platelet morphology indicated that some of them were activated. Finally, although only few platelets were identified on PET surfaces, their morphology corresponded to elongated pseudopodia and directed towards platelet activation [31], which has been reported to contribute to the recruitment of other platelets and blood cells such as leukocytes during long-term contact with the blood.

\section{Discussion}

The development of a versatile method for star PEG coating is of great interest to generate nonfouling surfaces for several applications; these include cardiovascular implants and microdevices directed towards biomedical and analytical applications, among others. To be effective, a dense, uniform, and stable PEG coating must be created at these surfaces $[13,16,22]$. In this study, we took advantage of high primary amine content $\left(\left[\mathrm{NH}_{2}\right]=7.5 \%\right)$ of LP coatings [20] for subsequent covalent grafting of NHS-PEG. Our amine-rich coating was combined with star-shaped PEG because of the latter's molecular architecture that offers high surface coverage and high steric hindrance towards protein adsorption [17]. Indeed, for similar chain lengths and molecular weights, star-shaped polymer brush variants have been demonstrated to possess higher density and greater steric repulsive forces against adsorbing proteins when compared to linear PEGs [32]. It has also been demonstrated that protein resistance can be enhanced with PEG molecules comprising a large number of hydrogen bond donors, such as carboxylic acid and hydroxyl functional groups [33]. In this study, we have successfully grafted star PEG in a covalent fashion onto aminated surfaces, as indicated by contact angle measurements and by XPS. However, the presence of surface-adsorbed PEG cannot be completely excluded, though unlikely because rinsing in the ultrasonic bath most likely removed loosely bound PEG from the surface. 


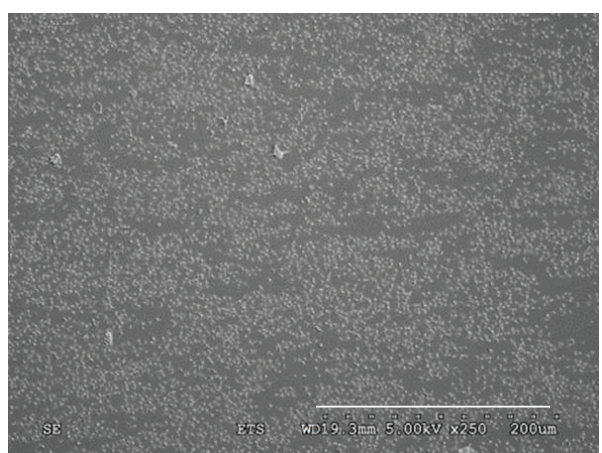

(a)

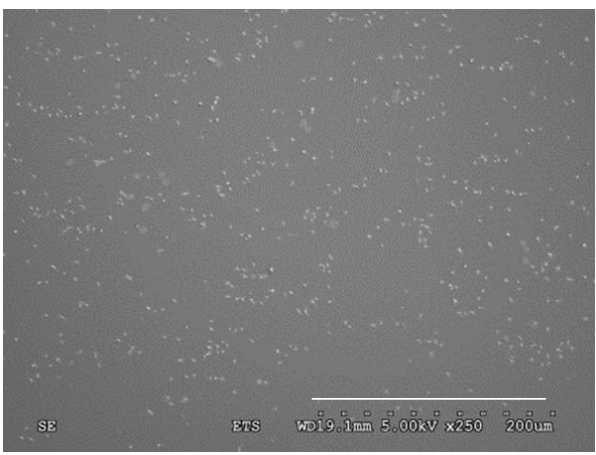

(c)

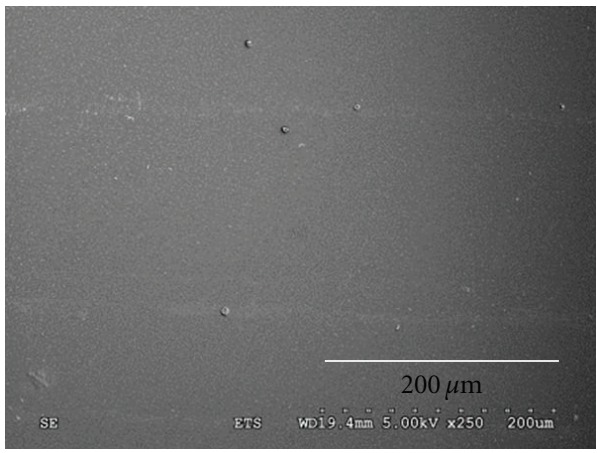

(e)

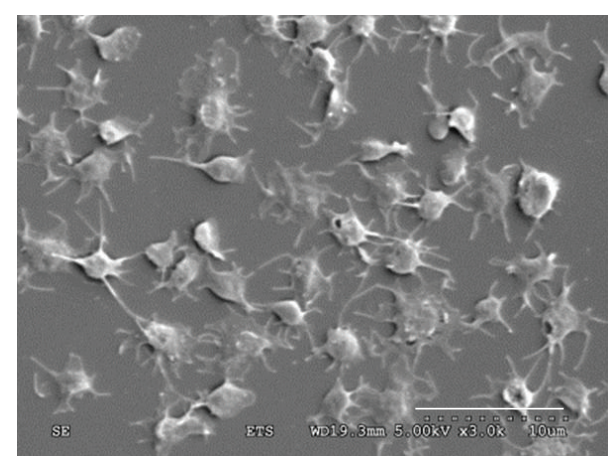

(b)

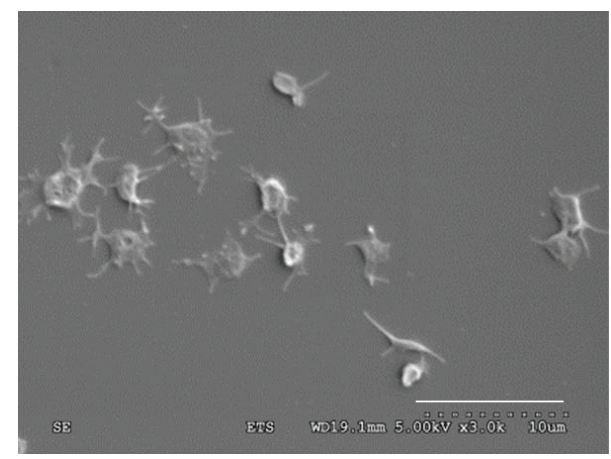

(d)

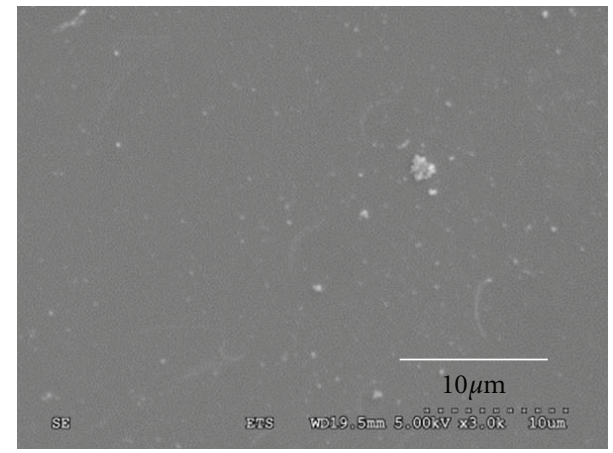

(f)

FIGURE 10: SEM visualization of platelet adhesion on LP (a, b), PET (c, d), and LP + 5\% PEG-c (e, f) grafted surfaces.

Increasing PEG concentration during coupling greatly increased the density of the final coating, up to $15 \%$ PEG. While contact angle measurements showed no difference between 5 and $15 \%$ PEG, the relative intensity of the C-O peak was higher for $15 \%$ PEG. This suggests a higher density of the PEG coating that may in turn reduce protein adsorption, especially for small proteins such as albumin. However, owing to the high cost of star-shaped PEG and the modest improvement according to QCM-D assay when increasing concentration from 5 to $15 \%$, we chose to evaluate the $5 \%$ PEG coating only, assuming that it would sufficiently reduce protein and platelet adhesion. Fibrinogen and albumin were chosen for protein adsorption studies due to the fact that they are two major constituents of blood plasma. Fibrinogen $(340 \mathrm{kDa})$, in particular, plays a key role in platelet adhesion and aggregation [1]. Albumin, a smaller protein $(66 \mathrm{kDa})$, was also tested. 5\% PEG coating strongly decreased protein adsorption compared to LP surfaces, and fibrinogen adsorption was reduced by $79 \%$ and albumin by $92 \%$, as deduced from QCM-D and fluorescence measurements, respectively. The slight discrepancy between QCM-D and fluorescent labeling results may be attributable to an overestimation of wet mass adsorption by QCM-D, in addition to inherent differences between dynamic (QCM-D) and static (fluorescence) assays for protein adsorption. Indeed, it has been already reported that QCM-D leads to 1.4- to 4-fold overestimation of adsorbed mass when compared to labeling or optical methods, depending on the type of protein [34]. However, protein adsorption could not be completely abrogated, even at high PEG coupling concentration. This result is most likely due to protein adsorption occurring at open spaces between the star PEG molecules [16], a process that can be favored 
by protein conformation changes initiated by steric constraints [35]. Studies have also shown that protein adsorption decreases as PEG chain length and density increase $[7,13,36]$. Hence, increasing PEG molecular weight and concentration may further decrease or completely inhibit protein adsorption with our amine-rich deposited polymer.

Although it is difficult to compare our data with adsorption results published by various research teams since the amount of adsorbed protein depends on its concentration and on the measurement method, our coating generally compares well with those reported in the literature. Indeed, Unsworth and colleagues reported an $80 \%$ reduction of fibrinogen adsorption on surface with high PEG chain density [37], where PEG had been grafted on gold surface through chemisorption method. The reduction of albumin adsorption assessed by fluorescence here $(>90 \%)$ is comparable to the results obtained by covalent coupling of PEG on silicone surfaces [38]. Other teams, however, showed that even more complete protein repellency can be achieved with PEG-containing copolymers (bulk modification). Weber and coworkers thus reported $95 \%$ reduction of fibrinogen adsorption on poly(DTEcarbonate) PEGylated copolymers (at 15 mol\%) [25], while Zhou et al. [39] reported negligible fibrinogen adsorption on a polyurethane copolymer when PEG content was increased to $52.5 \%$. However, these particular cases are very different from the method that we propose here, since the latter is much more versatile and can be implemented on any type of surface without modifying the bulk properties of biomaterials. Another interesting feature of the present method is its use to create fouling/non-fouling micro-patterns, as shown by our preliminary experiments with electron microscopy grids (Figure 8). Finally, the present PEG grafting method was demonstrated to exhibit excellent stability, as evidenced by strong reduction of fibrinogen adsorption over periods close to one month. Interestingly, PEG was found to be even more protein-resistant after 4 weeks of incubation in PBS than after 1 day in PBS. The reason for this observation is unclear, and further investigation would be needed using complementary surface analysis techniques and different incubation times to better assess PEG stability and conformation on the surfaces.

The low level of fibrinogen adsorption on PEG surfaces can be directly related to their ability to prevent platelet adhesion [6]. This was confirmed with our perfusion model using fresh human blood, which mimics physiological conditions. This test is believed to better estimate the nonthrombogenic potential of PEG-grafted surfaces than platelet adhesion tests performed under static condition [40], since the contact of platelets with a given surface is a dynamic process that involves adhesion, activation, secretion, and spreading. The relatively high level of platelet adhesion after LP treatment and their morphology by SEM indicate that LP attracts blood elements such as proteins and platelets. PEG grafting rendered the surface thromboresistant, as revealed by the negligible number of platelet adhesion determined in our platelet adhesion assay and further confirmed by SEM observations. The PEG surface also resists to cell adhesion and growth, as confirmed with Human Umbilical Vein Endothelial cell (HUVEC) (data unshown).
The present PEG grafting method is versatile and is shown here to possess good stability in PBS, but how long PEG-coated implants would consistently exhibit protein resistance and prevent thrombosis in vivo needs further investigation since PEG long-term stability and efficiency to prevent thrombus formation in vivo is subject of controversy $[41,42]$. Strategies combining non-fouling properties with the immobilization of antithrombogenic molecules, such as heparin, hirudin, or other direct thrombin inhibitors [42, 43] or of proadhesive peptides and growth factors to favor endothelialisation [44] should enable to solve this issue. The star PEG versatile grafting method developed here is compatible and promising for these strategies. Indeed PEG derivatives have been shown to be interesting molecular linker/spacer for bioactive molecules. Moreover, due to the steric constraints, either one or two terminal groups of star PEG are grafted to the surface, while the remaining groups do not participate in amide coupling and emanate outside of the surface. Hence, these terminal groups will be available for subsequent coupling of biomolecules.

\section{Summary and Conclusion}

A versatile method was optimized to create a non-fouling and non-thrombogenic coating that may be applicable to most biomaterial surfaces and enables micropatterning. The surfaces were not completely protein repellent and could be further optimized. However, platelet adhesion study suggests that star PEG-modified surfaces are non-thrombogenic. Moreover, the grafted PEG can also be utilized for further immobilization of bioactive molecules. In future steps, immobilization of growth factors, adhesion molecules, or antithrombogenic biomolecules to the PEG-grafted surface may be used to optimize its nonthrombogenicity, improve endothelialization, or favor healing around cardiovascular implants.

\section{Conflict of Interests}

The authors declare that they have no financial relationships relevant to this paper to disclose. The authors declare that they have no conflict of interests relevant to this paper.

\section{Acknowledgments}

This study was jointly funded by the Natural Sciences and Engineering Research Council of Canada (NSERC) and the Canadian Institutes of Health Research (CIHR). The authors would like to thank M. Ahmed Hachem and Younes Zaid for human blood sampling and platelet labeling. The authors are grateful to Professor Michael R. Wertheimer for his expertise in plasma polymerization. The authors would also like to thank Marion Maire (CRCHUM), Suzie Poulin (Ecole Polytechnique de Montreal), and Houman Savoji for their help regarding SEM, XPS analysis, and plasma deposition, respectively. 


\section{References}

[1] B. D. Ratner, "Blood compatibility-a perspective," Journal of Biomaterials Science, Polymer Edition, vol. 11, no. 11, pp. 1107-1119, 2000.

[2] S. I. Jeon and J. D. Andrade, "Protein-surface interactions in the presence of polyethylene oxide. II. Effect of protein size," Journal of Colloid And Interface Science, vol. 142, no. 1, pp. 159-166, 1991.

[3] F. Fuertges and A. Abuchowski, "The clinical efficacy of poly(ethylene glycol)-modified proteins," Journal of Controlled Release, vol. 11, no. 1-3, pp. 139-148, 1990.

[4] J. M. Harris, Poly(Ethylene Glycol) Chemistry, Biotechnical and Biomedical Applications, Plenum Press, New York, NY, USA, 1992.

[5] X. Zhao and J. Mllton Harris, "Novel degradable polyethylene glycol hydrogels for controlled release of protein," Journal of Pharmaceutical Sciences, vol. 87, no. 11, pp. 1450-1458, 1998.

[6] M. Zhang, T. Desai, and M. Ferrari, "Proteins and cells on PEG immobilized silicon surfaces," Biomaterials, vol. 19, no. 10, pp. 953-960, 1998.

[7] J. Groll and M. Moeller, "Star polymer surface passivation for single-molecule detection," Methods in Enzymology, vol. 472, pp. $1-18,2010$.

[8] S. S. Davis and L. Illum, "Polymeric microspheres as drug carriers," Biomaterials, vol. 9, no. 1, pp. 111-115, 1988.

[9] N. B. Graham and M. E. McNeil, "Hydrogels for controlled drug delivery," Biomaterials, vol. 5, no. 1, pp. 27-36, 1984.

[10] Z. Yang, J. A. Galloway, and H. Yu, "Protein interactions with poly(ethylene glycol) self-assembled monolayers on glass substrates: diffusion and adsorption," Langmuir, vol. 15, no. 24, pp. 8405-8411, 1999.

[11] H. S. Shin, K. Park, Ji Heung Kim et al., "Biocompatible peg grafting on dlc-coated nitinol alloy for vascular stents," Journal of Bioactive and Compatible Polymers, vol. 24, no. 4, pp. 316-328, 2009.

[12] L. Cao, S. Sukavaneshvar, B. D. Ratner, and T. A. Horbett, "Glow discharge plasma treatment of polyethylene tubing with tetraglyme results in ultralow fibrinogen adsorption and greatly reduced platelet adhesion," Journal of Biomedical Materials Research, vol. 79, no. 4, pp. 788-803, 2006.

[13] W. R. Gombotz, W. Guanghui, T. A. Horbett, and A. S. Hoffman, "Protein adsorption to poly(ethylene oxide) surfaces," Journal of Biomedical Materials Research, vol. 25, no. 12, pp. 1547-1562, 1991.

[14] S. Demming, C. Lesche, H. Schmolke, C. P. Klages, and S. Büttgenbach, "Characterization of long-term stability of hydrophilized PEG-grafted PDMS within different media for biotechnological and pharmaceutical applications," Physica Status Solidi (A), vol. 208, no. 6, pp. 1301-1307, 2011.

[15] K. L. Prime and G. M. Whitesides, "Adsorption of proteins onto surfaces containing end-attached oligo(ethylene oxide): a model system using self-assembled monolayers," Journal of the American Chemical Society, vol. 115, no. 23, pp. 10714-10721, 1993.

[16] S. J. Sofia and E. W. Merrill, "Protein adsorption on poly(ethylene oxide)-grafted silicon surfaces," ACS Symposium Series, vol. 680, pp. 342-360, 1997.

[17] P. R. Kuhl and L. G. Griffith-Cima, "Tethered epidermal growth factor as a paradigm for growth factor-induced stimulation from the solid phase," Nature Medicine, vol. 2, no. 9, pp. 1022-1027, 1996.
[18] F. Truica-Marasescu, P. L. Girard-Lauriault, A. Lippitz, W. E. S. Unger, and M. R. Wertheimer, "Nitrogen-rich plasma polymers: comparison of films deposited in atmospheric- and low-pressure plasmas," Thin Solid Films, vol. 516, no. 21, pp. 7406-7417, 2008.

[19] S. Lerouge, A. Major, P. L. Girault-Lauriault et al., "Nitrogenrich coatings for promoting healing around stent-grafts after endovascular aneurysm repair," Biomaterials, vol. 28, no. 6, pp. 1209-1217, 2007.

[20] J. C. Ruiz, A. St-Georges-Robillard, C. Thérésy, S. Lerouge, and M. R. Wertheimer, "Fabrication and characterisation of aminerich organic thin films: focus on stability," Plasma Processes and Polymers, vol. 7, no. 9-10, pp. 737-753, 2010.

[21] N. Nakajima and Y. Ikada, "Mechanism of amide formation by carbodiimide for bioconjugation in aqueous media," Bioconjugate Chemistry, vol. 6, no. 1, pp. 123-130, 1995.

[22] D. J. Irvine, A. M. Mayes, and L. Griffith-Cima, "Self-consistent field analysis of grafted star polymers," Macromolecules, vol. 29, no. 18, pp. 6037-6043, 1996.

[23] F. F. Hook, J. Vörös, M. Rodahl et al., "A comparative study of protein adsorption on titanium oxide surfaces using in situ ellipsometry, optical waveguide lightmode spectroscopy, and quartz crystal microbalance/dissipation," Colloids and Surfaces $B$, vol. 24, no. 2, pp. 155-170, 2002.

[24] F. Höök, M. Rodahl, P. Brzezinski, and B. Kasemo, "Energy dissipation kinetics for protein and antibody-antigen adsorption under shear oscillation on a quartz crystal microbalance," Langmuir, vol. 14, no. 4, pp. 729-734, 1998.

[25] N. Weber, A. Pesnell, D. Bolikal, J. Zeltinger, and J. Kohn, "Viscoelastic properties of fibrinogen adsorbed to the surface of biomaterials used in blood-contacting medical devices," Langmuir, vol. 23, no. 6, pp. 3298-3304, 2007.

[26] M. Rodahl, F. Höök, C. Fredriksson et al., "Simultaneous frequency and dissipation factor QCM measurements of biomolecular adsorption and cell adhesion," Faraday Discussions, vol. 107, pp. 229-246, 1997.

[27] S. Sharma, R. W. Johnson, and T. A. Desai, "Evaluation of the stability of nonfouling ultrathin poly(ethylene glycol) films for silicon-based microdevices," Langmuir, vol. 20, no. 2, pp. 348-356, 2004.

[28] J. L. Diener, H. A. Daniel Lagassé, D. Duerschmied et al., "Inhibition of von Willebrand factor-mediated platelet activation and thrombosis by the anti-von Willebrand factor A1-domain aptamer ARC1779," Journal of Thrombosis and Haemostasis, vol. 7, no. 7, pp. 1155-1162, 2009.

[29] Y. Merhi, M. King, and R. Guidoin, "Acute thrombogenicity of intact and injured natural blood conduits versus synthetic conduits: neutrophil, platelet, and fibrin(ogen) adsorption under various shear-rate conditions," Journal of Biomedical Materials Research Part A, vol. 34, no. 4, pp. 477-485, 1997.

[30] C. D. Wagner, Handbook of X-Ray and Ultraviolet Photoelectron Spectroscopy, Edited by G. E. Muilenberg, Perkin-Elmer Corporation(Physical Electronics), 1st edition, 1979.

[31] K. Park, F. W. Mao, and H. Park, "Morphological characterization of surface-induced platelet activation," Biomaterials, vol. 11, no. 1, pp. 24-31, 1990.

[32] J. Satulovsky, M. A. Carignano, and I. Szleifer, "Kinetic and thermodynamic control of protein adsorption," Proceedings of the National Academy of Sciences of the United States of America, vol. 97, no. 16, pp. 9037-9041, 2000.

[33] Y. H. Zhao, B. K. Zhu, L. Kong, and Y. Y. Xu, "Improving hydrophilicity and protein resistance of poly(vinylidene 
fluoride) membranes by blending with amphiphilic hyperbranched-star polymer," Langmuir, vol. 23, no. 10, pp. 5779-5786, 2007.

[34] N. Weber, H. P. Wendel, and J. Kohn, "Formation of viscoelastic protein layers on polymeric surfaces relevant to platelet adhesion," Journal of Biomedical Materials Research, vol. 72, no. 4, pp. 420-427, 2005.

[35] H. Huang, J. Xie, X. Liu, L. Yuan, S. Wang, S. Guo et al., "Conformational changes of protein adsorbed on tailored flat substrates with different chemistries," ChemPhysChem, vol. 12, no. 18, pp. 3642-3646, 2011.

[36] B. Zhu, T. Eurell, R. Gunawan, and D. Leckband, "Chain-length dependence of the protein and cell resistance of oligo(ethylene glycol)-terminated self-assembled monolayers on gold," Journal of Biomedical Materials Research, vol. 56, no. 3, pp. 406-416, 2001.

[37] L. D. Unsworth, H. Sheardown, and J. L. Brash, "Protein resistance of surfaces prepared by sorption of end-thiolated poly(ethylene glycol) to gold: effect of surface chain density," Langmuir, vol. 21, no. 3, pp. 1036-1041, 2005.

[38] H. Chen, Z. Zhang, Y. Chen, M. A. Brook, and H. Sheardown, "Protein repellant silicone surfaces by covalent immobilization of poly(ethylene oxide)," Biomaterials, vol. 26, no. 15, pp. 2391-2399, 2005.

[39] G. Zhou, C. Ma, and G. Zhang, "Synthesis of polyurethane-gpoly(ethylene glycol) copolymers by macroiniferter and their protein resistance," Polymer Chemistry, vol. 2, no. 6, pp. 1409-1414, 2011.

[40] S. Dimitrievska, M. Maire, G. A. Diaz-Quijada et al., "Low Thrombogenicity coating of nonwoven PET fiber structures for vascular grafts," Macromolecular Bioscience, vol. 11, no. 4, pp. 493-502, 2011.

[41] J. A. Hubbell, "Chapter 11 Pharmacologic modification of materials," Cardiovascular Pathology, vol. 2, supplement 3, pp. 121-127, 1993.

[42] S. Li and J. J. D. Henry, "Nonthrombogenic approaches to cardiovascular bioengineering," Annual Review of Biomedical Engineering, vol. 13, no. 1, pp. 451-475, 2011.

[43] M. B. Gorbet and M. V. Sefton, "Biomaterial-associated thrombosis: roles of coagulation factors, complement, platelets and leukocytes," Biomaterials, vol. 25, no. 26, pp. 5681-5703, 2004.

[44] M. L. W. Knetsch and L. H. Koole, "VEGF-E enhances endothelialization and inhibits thrombus formation on polymeric surfaces," Journal of Biomedical Materials Research, vol. 93, no. 1, pp. 77-85, 2010 . 

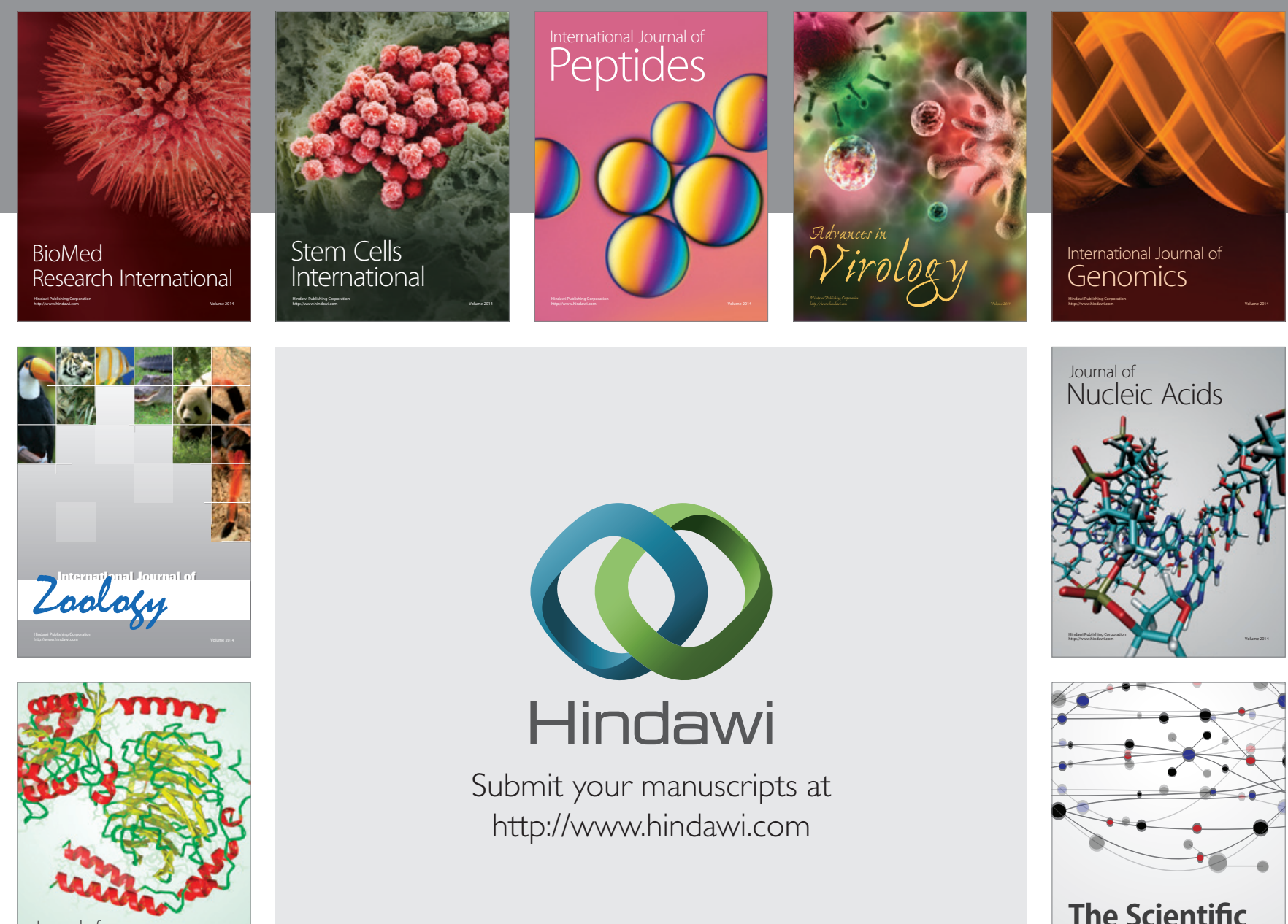

Submit your manuscripts at

http://www.hindawi.com

Journal of
Signal Transduction
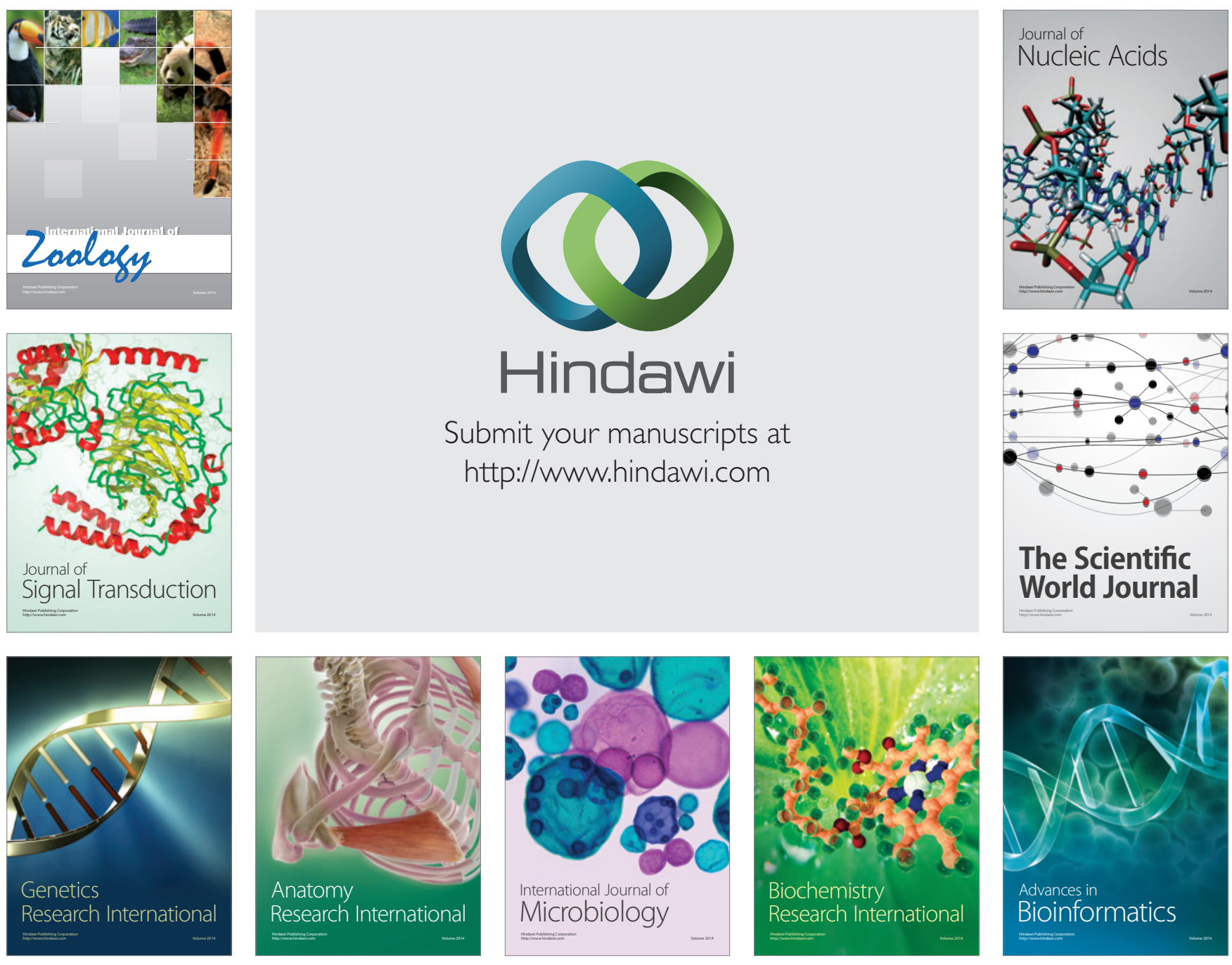

The Scientific World Journal
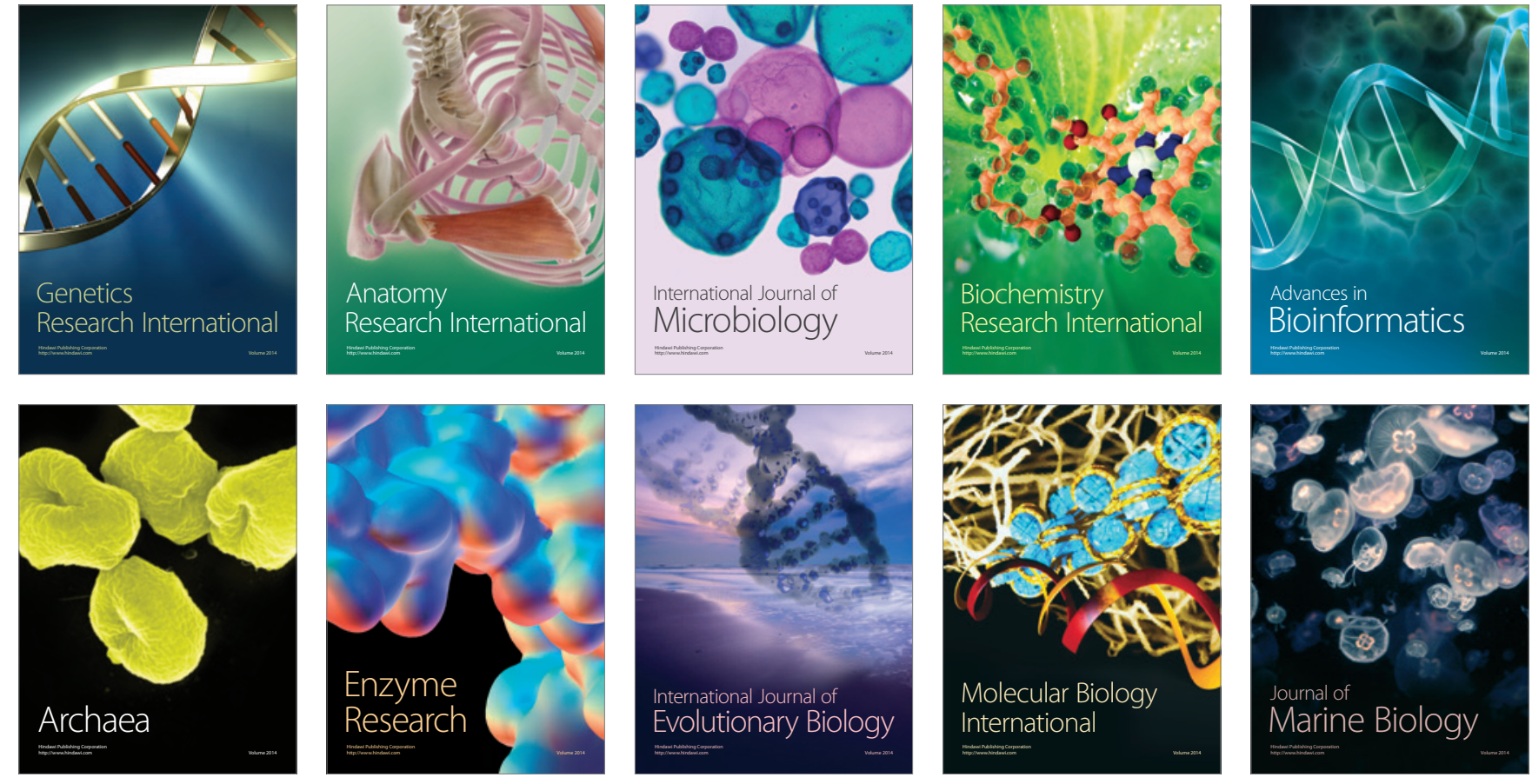